\title{
Genetic and epigenetic regulation of gene expression in fetal and adult human livers
}

\author{
Marc Jan Bonder ${ }^{1 \dagger}$, Silva Kasela ${ }^{2,3 \dagger}$, Mart Kals ${ }^{2,4}$, Riin Tamm²,3, Kaie Lokk ${ }^{3}$ Isabel Barragan ${ }^{5}$, Wim A Buurman ${ }^{6}$, \\ Patrick Deelen ${ }^{1,7}$, Jan-Willem Greve ${ }^{8}$, Maxim Ivanov ${ }^{5}$, Sander S Rensen ${ }^{6}$, Jana V van Vliet-Ostaptchouk ${ }^{9,10}$, \\ Marcel G Wolfs ${ }^{11}$, Jingyuan Fu', Marten H Hofker ${ }^{11}$, Cisca Wijmenga ${ }^{1}$, Alexandra Zhernakova', \\ Magnus Ingelman-Sundberg ${ }^{5}$, Lude Franke ${ }^{1 *+}$ and Lili Milani ${ }^{2^{*+}}$
}

\begin{abstract}
Background: The liver plays a central role in the maintenance of homeostasis and health in general. However, there is substantial inter-individual variation in hepatic gene expression, and although numerous genetic factors have been identified, less is known about the epigenetic factors.

Results: By analyzing the methylomes and transcriptomes of 14 fetal and 181 adult livers, we identified 657 differentially methylated genes with adult-specific expression, these genes were enriched for transcription factor binding sites of HNF1A and HNF4A. We also identified 1,000 genes specific to fetal liver, which were enriched for GATA1, STAT5A, STAT5B and YY1 binding sites. We saw strong liver-specific effects of single nucleotide polymorphisms on both methylation levels (28,447 unique CpG sites (meQTL)) and gene expression levels (526 unique genes (eQTL)), at a false discovery rate $(F D R)<0.05$. Of the 526 unique eQTL associated genes, 293 correlated significantly not only with genetic variation but also with methylation levels. The tissue-specificities of these associations were analyzed in muscle, subcutaneous adipose tissue and visceral adipose tissue. We observed that meQTL were more stable between tissues than eQTL and a very strong tissue-specificity for the identified associations between CpG methylation and gene expression.
\end{abstract}

Conclusions: Our analyses generated a comprehensive resource of factors involved in the regulation of hepatic gene expression, and allowed us to estimate the proportion of variation in gene expression that could be attributed to genetic and epigenetic variation, both crucial to understanding differences in drug response and the etiology of liver diseases.

Keywords: eQTL, meQTL, eQTM, Gene expression, Methylation, HumanMethylation450, Liver

\section{Background}

The liver plays a central role in the maintenance of homeostasis and health in general. Given the substantial inter-individual variation seen in metabolism, regulation of nutrients, protein synthesis, and detoxification of xenobiotics. It is essential to have a better understanding on inter-individual variation of gene expression, methylation and genetic effects specific to liver, and on different conditions, e.g. developmental stages. These variations

\footnotetext{
*Correspondence: lude@ludesign.nl; lili.milani@ut.ee

${ }^{\dagger}$ Equal contributors

'University of Groningen, University Medical Center Groningen, Department of Genetics, Hanzeplein 1, 9700 RB Groningen, the Netherlands

${ }^{2}$ Estonian Genome Center, University of Tartu, Riia 23 B, 51010 Tartu, Estonia

Full list of author information is available at the end of the article
}

can affect the liver's metabolic properties, leading to high levels of metabolites, either in the forms of lipids, proteins or xenobiotics, which can result in serious diseases or toxic side-effects. For example, several single nucleotide polymorphisms (SNPs) associated with liver function and related diseases have been identified through genomewide association (GWA) studies [1-6]. We and others have studied how these SNPs affect liver gene expression levels by mapping expression quantitative trait loci (eQTL) [7-11], and several genetic variants that regulate genes involved in the absorption, distribution, metabolism and excretion of drugs (ADME genes) have also been identified. 
Apart from genetic variation, epigenetic mechanisms (DNA methylation and histone modifications) also play an important role in regulating tissue-specific gene expression [12-14]. In particular, such mechanisms can influence the expression of hepatic ADME genes. For example, the methylation status of a $\mathrm{CpG}$ island in exon 2 of CYP1A2 was shown to correlate with interindividual differences in the expression of this gene in human livers [15]. Given that CYP1A2 is an important drugmetabolizing enzyme, those factors that influence its epigenetic state may also contribute to the individual drug response. Interestingly, the epigenetic state of ADME genes, at least in rodent livers, can change in response to xenobiotic exposure $[16,17]$, thus opening the perspective for epigenetics-mediated drug-drug interactions. More examples on epigenetic regulation of ADME genes have been reviewed by Kacevska et al. [18]. However, the majority of such data come from studies of epigenetic alterations observed either in tumors, or in cell lines treated with DNA demethylating agents. So far it is not clear, to which extent such cancer-related or experimentally induced epigenetic alterations correspond to the natural epigenetic variability in human livers. Hence, it is essential to include epigenetic variation when studying the regulation of hepatic gene expression, to further explain the causes of differences in drug response and the etiology of diseases associated with liver function.

Here we present a comprehensive survey of the methylome and transcriptome of the human liver (Figure 1A). First, we addressed the regulation of gene expression in the developing human liver by comparing genome-wide expression and methylation levels in 96 adult and 14 fetal livers from the Karolinska Liver Bank. Then we used genetic, epigenetic and gene expression data from the adults, along with an extra cohort of 85 Dutch adult liver samples to investigate the regulation of gene expression in the human liver. Finally, we explored the tissue specificity of the identified associations between SNPs, methylation and expression in other tissues from the Dutch adult samples.

\section{Results}

\section{Developmental regulation of hepatic gene expression} The epigenome of the developing human liver

We first compared the epigenomes of 8- to 21-week-old fetal livers with adult livers. We assessed the methylation levels of 366,074 variable CpG sites and found 28,917 CpG sites (annotated to 12,619 unique genes) that showed a significant difference (absolute mean beta value difference $>0.2, F D R<0.05$ ) between fetal and adult liver tissue (see Supplementary Online Methods in the Additional files 1 and 2). Although the number of hypomethylated CpG sites in fetal liver (53.4\%) was similar to the number of hypermethylated sites (46.6\%) in this cohort, we observed an age-specific association between the genomic location of CpG sites and whether they were hypo- or hypermethylated (chi-squared test p-value $<2.2 \times 10^{-16}$ ). In fetal livers, the majority (86\%) of the differentially methylated CpG sites that are located within CpG islands (CGI) were hypomethylated, whereas this was not the case for CpG sites outside CGIs, where roughly $50 \%$ of the CpG sites were either hypo- or hypermethylated in fetal livers (Figure 1B). This is particularly interesting because in both adult and fetal livers, close to $80 \%$ of the CpG sites within CGI are not methylated, with $>95 \%$ overlap between the two age groups. Accordingly, the CpG sites within CGIs that were hypomethylated in the fetal livers mostly had intermediate methylation levels in the adult liver samples (Additional file 3).
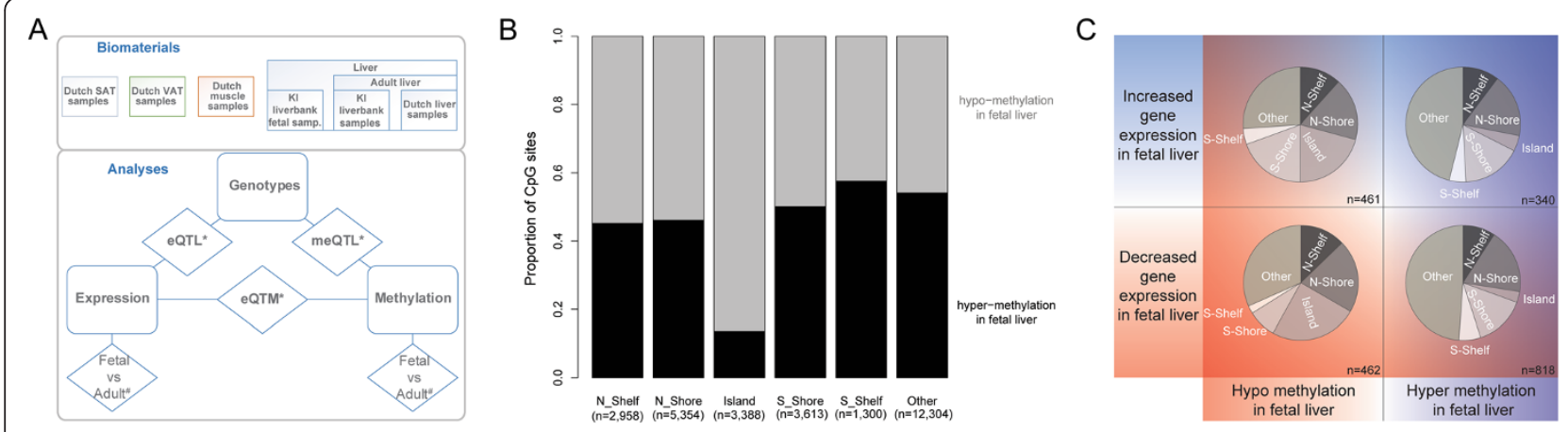

Figure 1 Study design and distribution of CpG sites. (A) Study design describing the investigated biomaterials and analyses performed. *) conservation compared across tissues; \#) compared in fetal vs adult livers. (B) Distribution of the location of differentially methylated CpG sites between fetal and adult livers. The bar plot shows the percentage of differentially methylated CpG sites (y-axis) that are hypermethylated (black bars) or hypomethylated (grey bars) in fetal livers compared to adult livers in CpG islands, shores, shelves and other regions of the genome. (C) Distribution of differentially expressed and methylated genes depending on the relation to CpG islands. Pie charts illustrating the distribution of CpG island regions in case of significant increased or decreased gene expression and significant hyper- or hypomethylation. 
To explore the functions of the genes that were differentially methylated in fetal liver compared to adult liver, we used the GREAT pathway tool [19]. The CpG sites that were hypomethylated in the adult livers and hypermethylated in fetal liver were strongly enriched for metabolic pathways, such as the steroid metabolic process the regulation of lipid metabolic processes, regulation of generation of precursor metabolites and energy, and regulation of glycolysis (all with p-values $<1.15 \times 10^{-44}$ ) (Table 1A). However, the genes that were associated with hypomethylated $\mathrm{CpG}$ sites in the fetal samples were strongly enriched for pathways of insulin receptor signaling, regulation of glycogen synthase activity, differentiation processes, and developmental functions (Table 1B).

\section{The transcriptome of the developing liver}

Comparison of gene expression levels between the fetal and adult liver samples yielded 3,284 differentially expressed probes (absolute $\log _{2}$-fold change $>1.0$, FDR $<$ 0.05 , Additional file 4). Pathway analysis, using Gene Network [20], confirmed that 1,396 genes with higher expression in the adult livers were strongly enriched for metabolic functions like monocarboxylic acid, steroid and bile acid metabolic processes, as well as the response to xenobiotic process (Table 2A). In contrast, 1,277 genes that were highly expressed in fetal tissue were associated with regulating organelle organization, chromosome organization, and tetrapyrrole (e.g. hemoglobin) biosynthetic processes (Table 2B). These observations are in line with the fetal development, which is characterized by tissue differentiation and growth and by the fact that the liver is predominantly a hematopoietic organ during this period [21].

\section{Orchestration of epigenetics and transcriptomics in regulating liver development}

We found 1,655 genes that showed both differential expression and differential methylation in adult vs. fetal livers (Additional file 5). More specifically, 657 genes were linked to probes with higher expression levels in adults, and 1,000 genes linked to probes that were more highly expressed in fetal livers (with an overlap of two genes). As expected, these genes are even more significantly enriched for developmental stage-specific functions, such as drug response for the adult cohort (p-value $4.0 \times$ $10^{-131}$ ) and liver development for the fetal cohort ( $\mathrm{p}$-value

Table 1 Gene Ontology analysis of differentially methylated genes in fetal versus adult livers

\begin{tabular}{|c|c|c|c|}
\hline \multicolumn{4}{|c|}{ A. Top 10 biological processes associated with hypomethylated genes in adult livers } \\
\hline Term Name & P-value & Fold enrich. $^{1}$ & Obs. regions $^{2}$ \\
\hline Steroid metabolic process & 2.77E-52 & 2.03 & 558 \\
\hline Regulation of lipid metabolic process & 4.42E-51 & 2.06 & 528 \\
\hline Regulation of generation of precursor metabolites and energy & $5.62 \mathrm{E}-48$ & 3.24 & 216 \\
\hline Regulation of glycolysis & 1.15E-44 & 5.21 & 116 \\
\hline Sterol metabolic process & $4.28 \mathrm{E}-44$ & 2.56 & 288 \\
\hline Positive regulation of lipid metabolic process & $3.52 \mathrm{E}-43$ & 2.48 & 300 \\
\hline Regulation of cellular carbohydrate catabolic process & $3.26 \mathrm{E}-42$ & 4.22 & 136 \\
\hline Regulation of lipid transport & $3.88 \mathrm{E}-42$ & 3.54 & 168 \\
\hline Cholesterol metabolic process & $3.71 \mathrm{E}-40$ & 2.51 & 271 \\
\hline Regulation of cellular ketone metabolic process & 4.25E-39 & 2.11 & 381 \\
\hline \multicolumn{4}{|c|}{ B. Top 10 biological processes associated with hypomethylated genes in fetal livers } \\
\hline Term Name & P-value & Fold enrich. ${ }^{1}$ & Obs. regions ${ }^{2}$ \\
\hline Insulin receptor signalling pathway & $1.74 \mathrm{E}-130$ & 77.00 & 88 \\
\hline Positive regulation of glycogen (starch) synthase activity & 1.69E-105 & 37.19 & 90 \\
\hline Anterior/posterior pattern specification & $1.27 E-96$ & 2.26 & 813 \\
\hline Regulation of gene expression by genetic imprinting & $2.36 \mathrm{E}-92$ & 10.52 & 143 \\
\hline Regulation of glycogen (starch) synthase activity & $3.97 E-81$ & 19.01 & 91 \\
\hline Genetic imprinting & $3.54 \mathrm{E}-69$ & 6.66 & 147 \\
\hline Response to estrogen stimulus & $4.52 \mathrm{E}-69$ & 2.14 & 657 \\
\hline Positive regulation of insulin receptor signalling pathway & $9.60 \mathrm{E}-68$ & 11.64 & 98 \\
\hline Positive regulation of cell cycle & $2.83 \mathrm{E}-61$ & 2.51 & 421 \\
\hline Luteinizing hormone secretion & $4.18 \mathrm{E}-61$ & 11.24 & 90 \\
\hline
\end{tabular}

${ }^{1}$ Fold enrichment - fold enrichment of number of genomic regions in the test set with the annotation.

${ }^{2}$ Observed region hits - actual number of genomic regions in the test set with the annotation. 
Table 2 Gene Ontology analysis of differentially expressed genes in fetal versus adult liver

\begin{tabular}{lcc}
\hline $\begin{array}{l}\text { A. Top } \mathbf{1 0} \text { biological processes associated with hyperexpressed } \\
\text { genes in adult livers }\end{array}$ & P-value & $\begin{array}{c}\text { Nr of } \\
\text { genes }\end{array}$ \\
\hline Term & $2.80 \mathrm{E}-205$ & 347 \\
\hline Monocarboxylic acid metabolic process & $8.26 \mathrm{E}-202$ & 201 \\
Lipid localization & $1.99 \mathrm{E}-197$ & 180 \\
Lipid transport & $2.91 \mathrm{E}-196$ & 257 \\
Steroid metabolic process & $1.13 \mathrm{E}-192$ & 40 \\
Bile acid metabolic process & $9.88 \mathrm{E}-184$ & 114 \\
Response to xenobiotic stimulus & $9.88 \mathrm{E}-184$ & 114 \\
Cellular response to xenobiotic stimulus & $6.72 \mathrm{E}-183$ & 113 \\
Xenobiotic metabolic process & $6.23 \mathrm{E}-178$ & 23 \\
Bile acid biosynthetic process & $2.61 \mathrm{E}-173$ & 131 \\
\hline
\end{tabular}

B. Top 10 biological processes associated with hyperexpressed genes in fetal livers

\begin{tabular}{lcc}
\hline Term & P-value & $\begin{array}{c}\text { Nr of } \\
\text { genes }\end{array}$ \\
\hline Negative regulation of organelle organization & $3.93 \mathrm{E}-162$ & 138 \\
Regulation of organelle organization & $1.73 \mathrm{E}-132$ & 370 \\
$\begin{array}{l}\text { Negative regulation of cellular component } \\
\text { organization }\end{array}$ & $3.40 \mathrm{E}-127$ & 265 \\
$\begin{array}{l}\text { Regulation of chromosome organization } \\
\text { Porphyrin-containing compound biosynthetic }\end{array}$ & $1.61 \mathrm{E}-114$ & 72 \\
process & $1.84 \mathrm{E}-112$ & 34 \\
Tetrapyrrole biosynthetic process & $1.84 \mathrm{E}-112$ & 34 \\
Negative regulation of chromosome organization & $6.05 \mathrm{E}-108$ & 29 \\
Chromatin assembly or disassembly & $8.76 \mathrm{E}-106$ & 128 \\
Pigment biosynthetic process & $1.73 \mathrm{E}-103$ & 53 \\
G1 phase & $6.25 \mathrm{E}-102$ & 36 \\
\hline
\end{tabular}

$\left.6.0 \times 10^{-90}\right)$. In the majority of the genes with more than one detection probe, the differences in expression levels were very similar between fetal and adult livers. However, in two genes (TGM2 and INS-IGF2), one of the probes was more highly expressed in fetal livers, while the other probe reflected higher expression in adult livers. The location of the differentially methylated CpG sites differed significantly in relation to CGIs, depending on the expression and methylation differences between fetal and adult livers (chi-squared test p-value $<2.2 \times 10^{-16}$, Figure 1 C): for genes with a lower expression in fetal livers, the hypomethylated CpG sites more often map within CpG islands, shores and shelves, while the hypermethylated CpG sites map further away from CGI regions.

Regions within $2 \mathrm{~kb}$ of the transcription start site (TSS) of the 1,655 genes are enriched for binding sequences of transcription factors essential for the development or function of the liver, specifically HNF4A (adjusted $\mathrm{p}$-value $\left.=2 \times 10^{-73}\right)$ and HNF1A (adj. p-value $=6 \times 10^{-38}$ ); hematopoietic transcription factors GATA1 (adj. p-value $=$ $8 \times 10^{-36}$ ), STAT5A (adj. p-value $=2 \times 10^{-43}$ ), and STAT5B (adj. $\mathrm{p}$-value $=1 \times 10^{-49}$ ); and YY1 (adj. p-value $=2 \times$ $10^{-36}$ ), which plays a fundamental role in embryogenesis and differentiation. We therefore investigated the expression levels of these transcription factors and observed that transcripts for the HNF1A and HNF4A genes were more highly expressed in adult livers, and GATA1, STAT5A, STAT5B and $Y Y 1$ were all more highly expressed in fetal livers (Figure 2, Additional file 6).

Table 3 lists the 20 genes with the largest differences in expression and methylation, clearly illustrating the fetal-specific expression of genes involved in differentiation and hematopoiesis (e.g. DLK1, HBZ, HBM, AHSP, $E P B 42$ and NFE2), and the adult-specific expression of genes involved in drug metabolism, catabolism and other biosynthesis processes. CYP2E1 and CYP2C 8 are the cytochrome P450 (CYP) genes; these show the most significant difference in expression levels between fetal and adult liver, with an approximately 7 -fold higher expression level in adult liver.

\section{Genetic and epigenetic effects on inter-individual variability in gene expression \\ Correlation in DNA methylation and gene expression}

We next assessed whether DNA methylation is correlated to gene expression levels in the adult samples. We combined data from the Karolinska Liver Bank and Dutch liver samples (total number of samples with expression and methylation data $=158$ ) and compared expression probes with CpG sites that map within $250 \mathrm{~kb}$ of these probes. We did not include the fetal samples due to the large developmental differences reported above, and we estimated that the fetal samples would not add any considerable statistical power for the analyses. We identified 3,238 significant methylation-expression associations (eQTMs, Additional file 7), comprising 1,988 unique expression probes (in 1,798 genes) and 2,980 CpG sites (reflecting 2,057 unique genes), with a permutation pvalue $<0.05$. As expected, there are more eQTMs with a negative correlation between expression levels and CpG methylation levels (58.4\%), irrespective of the CpG site location in relation to CPG islands. Furthermore, for CpG sites with strong correlation between expression and methylation levels, and/or within $50 \mathrm{~kb}$ of the expression probes, we observed an overrepresentation of negative correlations (chi-squared test $\mathrm{p}$-value $<2.2 \times$ $10^{-16}$, Figure 3).

\section{Regulation of gene expression by genetic polymorphisms}

We next explored the effects of genetic variation on liver gene expression levels. Expression quantitative trait locus (eQTL) mapping in the adult livers (meta-analysis of the two cohorts, combined number of samples with 

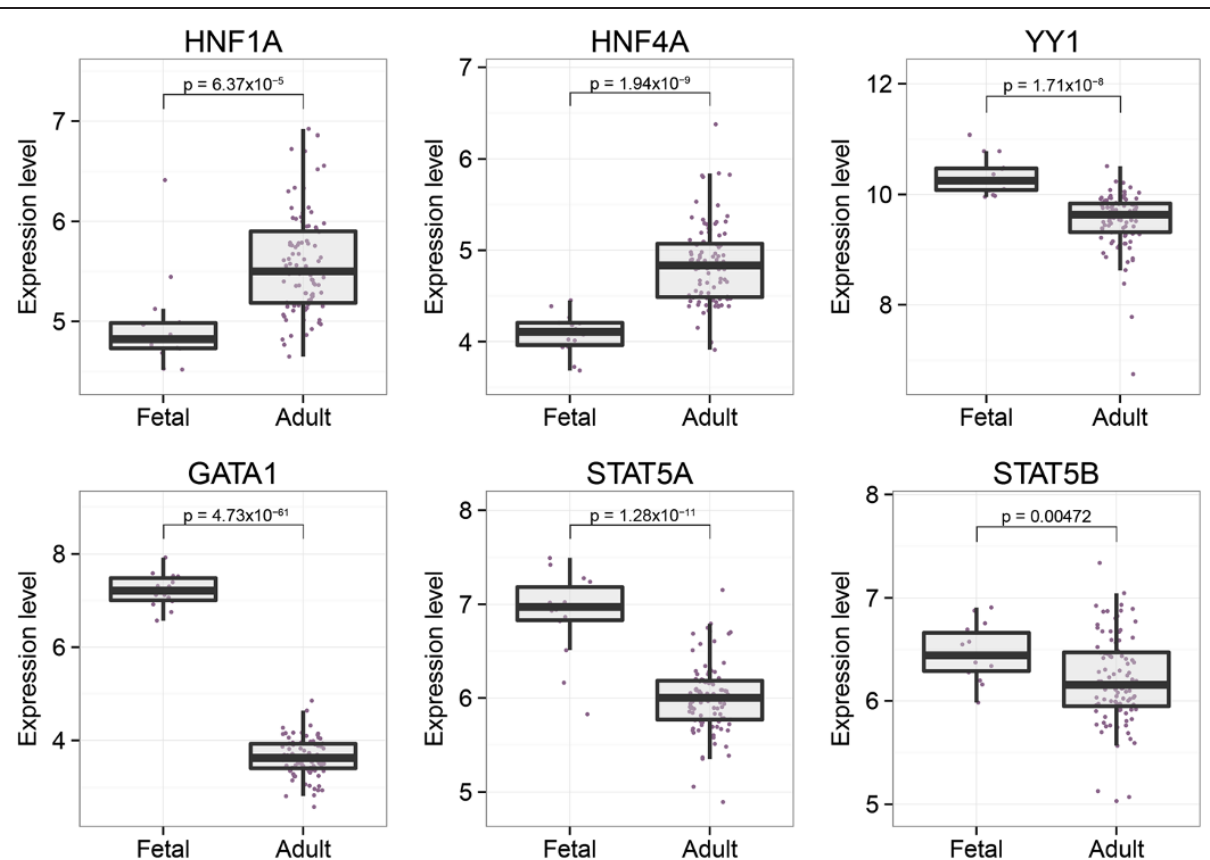

Figure 2 Expression levels of transcription factors in fetal and adult livers. Box plots of the $\log _{2}$ transformed expression levels (y-axis) are shown for the adult and fetal liver samples (x-axis). The transcripts for HNF1A and HNF4A were expressed at significantly higher levels in the adult livers, while YY1, GATA1, STAT5A and STAT5B were expressed at higher levels in the fetal livers.

Table 3 Top 20 genes with largest difference in expression and differential methylation between fetal and adult livers

\begin{tabular}{|c|c|c|c|c|c|c|c|c|}
\hline \multirow[t]{2}{*}{ Gene } & \multicolumn{2}{|c|}{ Median expression } & \multirow[t]{2}{*}{$\log \mathrm{FC}$} & \multirow{2}{*}{$\begin{array}{l}\text { Adj p-value } \\
\quad \text { (FDR) }\end{array}$} & \multicolumn{2}{|c|}{ Mean beta value } & \multirow{2}{*}{$\begin{array}{l}\text { Beta value } \\
\text { difference }\end{array}$} & \multirow{2}{*}{$\begin{array}{l}\text { Adj p-value } \\
\text { (FDR) }\end{array}$} \\
\hline & Adult & Fetal & & & Adult & Fetal & & \\
\hline$D L K 1$ & 3.27 & 12.64 & 9.15 & $3.55 E-46$ & 0.42 & 0.63 & 0.22 & $3.19 E-36$ \\
\hline$H B Z$ & 3.23 & 12.35 & 9.07 & $1.82 \mathrm{E}-45$ & 0.8 & 0.55 & -0.25 & 4.02E-18 \\
\hline$H B M$ & 3.01 & 12.52 & 9.03 & $4.27 \mathrm{E}-42$ & 0.42 & 0.21 & -0.21 & $2.55 \mathrm{E}-11$ \\
\hline AHSP & 4.37 & 13.26 & 8.46 & $2.66 \mathrm{E}-42$ & 0.74 & 0.41 & -0.33 & $1.43 \mathrm{E}-34$ \\
\hline EPB42 & 3.13 & 11.25 & 8.19 & $2.26 \mathrm{E}-48$ & 0.89 & 0.47 & -0.42 & $3.84 \mathrm{E}-64$ \\
\hline CYP2E1 & 13.42 & 4.1 & -7.64 & 8.63E-36 & 0.51 & 0.88 & 0.36 & $1.10 \mathrm{E}-41$ \\
\hline HBEI & 2.87 & 10.66 & 7.63 & $4.10 E-48$ & 0.76 & 0.49 & -0.27 & $1.41 \mathrm{E}-34$ \\
\hline$C R P$ & 13.33 & 4.33 & -7.27 & $7.71 E-34$ & 0.53 & 0.89 & 0.36 & $2.99 \mathrm{E}-42$ \\
\hline C9 & 11.91 & 3.59 & -7.18 & $3.98 \mathrm{E}-39$ & 0.48 & 0.84 & 0.36 & $8.73 E-39$ \\
\hline APCS & 12.69 & 4.39 & -7 & $5.95 E-40$ & 0.45 & 0.88 & 0.43 & $7.26 \mathrm{E}-48$ \\
\hline SLC4A1 & 4.04 & 11.3 & 6.96 & 1.46E-61 & 0.75 & 0.4 & -0.35 & $2.14 \mathrm{E}-42$ \\
\hline NNMT & 11.06 & 3.44 & -6.88 & $4.10 \mathrm{E}-40$ & 0.36 & 0.84 & 0.48 & $7.10 \mathrm{E}-45$ \\
\hline CYP2C8 & 12.9 & 4.83 & -6.85 & $3.42 \mathrm{E}-31$ & 0.59 & 0.88 & 0.29 & $2.57 E-36$ \\
\hline$A Q P 9$ & 11.51 & 3.47 & -6.81 & $1.26 \mathrm{E}-33$ & 0.39 & 0.84 & 0.45 & $8.23 \mathrm{E}-45$ \\
\hline NFE2 & 4.1 & 11.03 & 6.8 & $2.29 \mathrm{E}-47$ & 0.82 & 0.45 & -0.36 & $3.02 \mathrm{E}-41$ \\
\hline$A D H 1 C$ & 11.93 & 3.92 & -6.69 & $1.96 \mathrm{E}-24$ & 0.42 & 0.81 & 0.39 & $8.06 \mathrm{E}-38$ \\
\hline MYL4 & 3.88 & 10.77 & 6.65 & $6.78 \mathrm{E}-60$ & 0.88 & 0.4 & -0.48 & 1.90E-62 \\
\hline C3P1 & 11.36 & 3.81 & -6.63 & $2.34 \mathrm{E}-37$ & 0.73 & 0.24 & -0.49 & $1.56 \mathrm{E}-47$ \\
\hline RHAG & 3.35 & 10.22 & 6.56 & $1.50 \mathrm{E}-46$ & 0.81 & 0.49 & -0.31 & $1.64 \mathrm{E}-47$ \\
\hline HSD17B6 & 12.12 & 4.61 & -6.31 & $4.88 \mathrm{E}-29$ & 0.89 & 0.66 & -0.22 & $1.48 \mathrm{E}-41$ \\
\hline
\end{tabular}




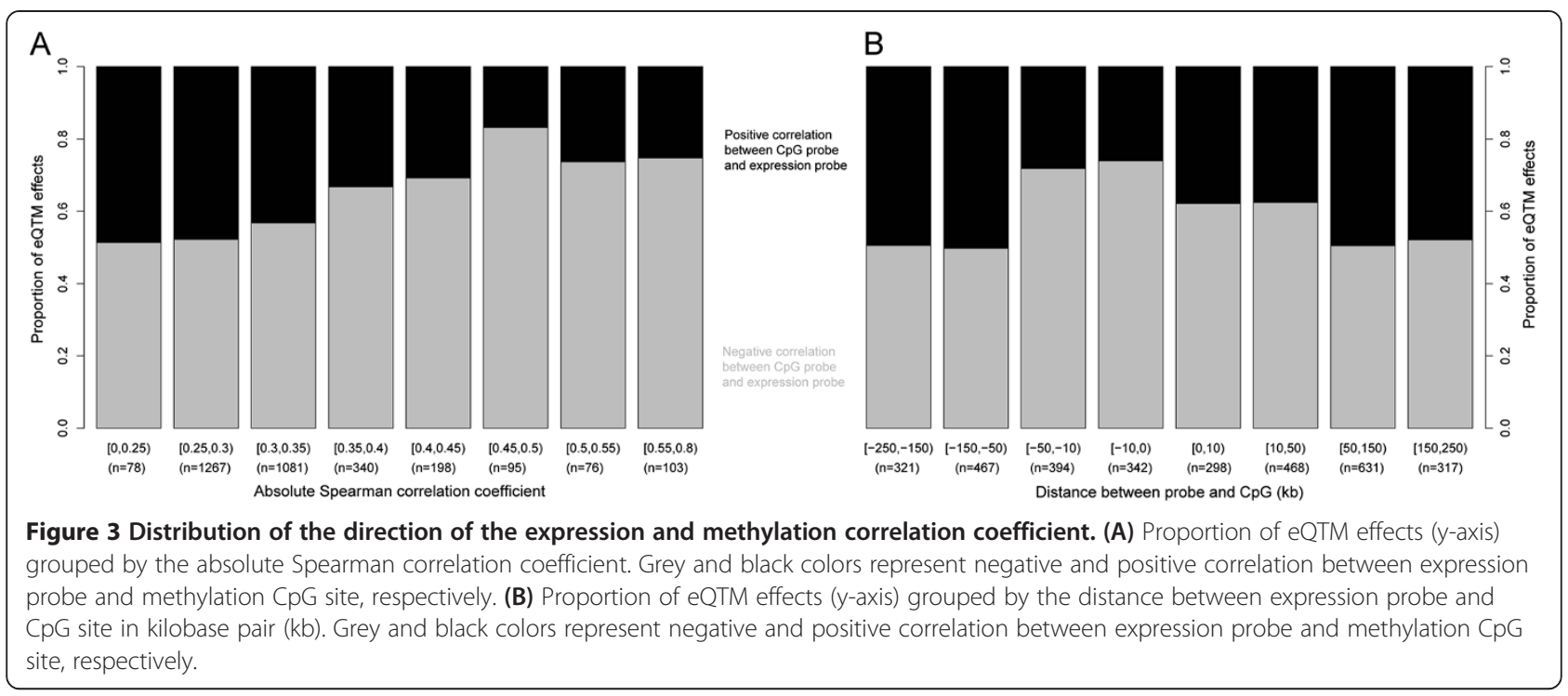

expression and genotype data $=171$ ) yielded a total of 47,168 significant SNP-probe pair correlations (FDR $<0.05$ ), representing 751 unique genes (Additional file 8). The eQTL probes are significantly enriched for liver-specific genes (area under the curve (AUC) 0.67, p-value $4 \times 10^{-57}$, as reported by Gene Network) and are strongly enriched for genes encoding drug-metabolizing enzymes ( $\mathrm{p}$-value $\left.2.0 \times 10^{-19}\right)$. We compared our results with reported liver cis-eQTLs [7-10,22] and observed that we could replicate 667 reported eQTL genes, however we also identified 84 new eQTL genes (Additional file 8).

\section{Influence of genetic variation on DNA methylation}

We investigated the effects of SNPs on CpG methylation (meQTL) in adult liver samples (meta-analysis, combined number of samples with methylation and genotype data $=161$ ). In total we found significant cis-meQTL for 28,447 unique methylation probes (FDR $<0.05$, mapping to 12,054 unique genes), reflecting $1,477,126$ different SNP-CpG site combinations. In contrast to the eQTL, we did not observe any enrichment of liver functions for these 12,054 meQTL associated genes. Looking further into the SNPs affecting DNA methylation and gene expression, we identified 215 unique genes and 10,432 unique SNPs associated with both an eQTL and meQTL, resulting in a total of 30,644 overlapping QTL effects. Interestingly, for most of the 215 genes (69.3\%) influenced by both an eQTL and meQTL we observed an opposite effect direction, i.e. the same genotype was associated with higher methylation levels and lower expression levels, or vice versa (Additional file 9). This effect is strongest in the $\mathrm{CpG}$ islands and $\mathrm{CpG}$ island shores, where it occurs in more than $75 \%$ of the cases (Additional file 10).

\section{Contribution of genetic variants and DNA methylation to variation in hepatic gene expression}

Once we had identified eQTL and eQTMs, we ascertained to what extent SNPs and DNA methylation could jointly explain the variation in liver gene expression levels. We selected 293 expression probes (reflecting 274 unique genes) that had both a significant cis-eQTL and significant eQTM effect. We then tested four different linear models (see Supplementary Online Methods in the Additional file 1) to assess the proportion of variation in gene expression that could be explained. For $83 \%$ of these 293 expression probes, most of the expression variation was explained by a SNP (Additional file 11), whereas for the remaining $17 \%$ the expression variation was most strongly explained by a specific CpG site. For the latter cases, we observed that these expressionassociated CpG sites were likely to have a meQTL effect (chi-squared p-value $=0.035)$. As expected, when we combined the SNP genotype and CpG site methylation levels, we could explain more of the expression variation than by using either SNP or methylation levels alone. Given the correlations between genotypes and methylation levels, we also estimated the unique contributions of the two on gene expression levels (Additional file 12). Overall, SNP genotypes uniquely explain a greater proportion of the variation in gene expression (median 0.1, standard deviation 0.122) than methylation levels (median 0.029, standard deviation 0.049). The SNPs and CpG sites with particularly high correlations with the expression levels were generally closer to the transcription start site of the corresponding genes (Additional file 13).

The contributions of SNPs and DNA methylation levels to the proportion of variation explained in gene expression levels are illustrated in Additional file 14 and 
Table 4 by 16 unique ADME genes that had both significant eQTL and eQTMs. The ADME gene list was extracted from http://www.pharmaADME.org. For the GSTT1, GSTM1, UGT1A1, GSTO1 and PON1 genes, DNA methylation explains a larger proportion of the variation in gene expression levels compared to SNP genotypes. Overall, we found that adding more CpGs to the model, which were all associated to the selected expression probes of the same gene, did not significantly increase the power to explain more of the variation in gene expression $\left(\mathrm{p}\right.$-value $\left.<2.2 \times 10^{-16}\right)$. In addition to the ADME genes, we also investigated the role of SNPs and CpG site methylation in the regulation of genes associated with diseases and liver function by querying all SNPs from the GWAS catalog (http://www.genome.gov/gwastudies/) in our list of identified eQTLs. We identified cis-acting SNPs and DNA methylation differences that were associated with the expression of 47 genes previously identified in different GWA studies with complex traits, including enzyme and metabolite levels as well as cardiovascular and inflammatory bowel diseases (Additional file 15).

\section{Tissue-specificity of eQTL, meQTL and eQTMs}

Since we had also generated methylation and expression data for three other tissues (muscle, subcutaneous- (SAT) and visceral adipose tissue (VAT)) from the same individuals in the Dutch cohort, we could assess the tissue- specificity of the detected eQTL, meQTL and eQTM effects. We had previously compared liver eQTL with other tissues for only a limited number of samples [11], so we re-did this analysis with the new adult liver samples from the Karolinska Liver Bank. For liver eQTL, approximately $40-50 \%$ of the effects found in one tissue could also be significantly detected in another tissue (Figure 4A). We identified only a few opposite allelic effects $(<1 \%)$ between the tissues (Additional file $16 \mathrm{~A}$ and B), suggesting that if a SNP affects expression in multiple tissues, the allelic direction is mostly identical. The eQTL effects $(n=32,863)$ that were only present in liver and not in the other three tissues were related to genes strongly specific to liver function (p-value $5 \times 10^{-53}$ ) and metabolic and catabolic processes ( $\mathrm{p}$-values $<5 \times 10^{-20}$ ).

Contrary to the strong tissue-specificity of eQTL, meQTL were much more stable across the different tissues. On average, $70 \%$ of the meQTL are shared between at least two tissues, with over $98 \%$ of their effects having the same allelic direction (Figure 4B, Additional file 16C \& D). As we had observed for eQTL, there were also a few significant meQTL that showed an opposite allelic direction between liver and the other three tissues (Additional file 17). The CpG sites of the meQTL with opposite effects were more often located outside the gene bodies ( $\mathrm{p}$-value $\left.1.53 \times 10^{-11}\right)$, but when they were in gene bodies, they were in exons rather than introns (p-value $1.7 \times 10^{-90}$ ).

Table 4 Proportion of explained variation by SNPs and CpG sites associated with the expression of ADME genes

\begin{tabular}{|c|c|c|c|c|c|c|c|}
\hline \multirow[t]{2}{*}{ Gene/Locus } & \multirow[t]{2}{*}{ Chr } & \multirow[t]{2}{*}{ SNP } & \multirow[t]{2}{*}{ CpG site } & \multicolumn{4}{|c|}{$\%$ of variation in expression explained by } \\
\hline & & & & SNP only & CpG only & SNP and CpG site & SNP and all CpG sites ${ }^{1}$ \\
\hline GSTT1 & 22 & rs9612520 & cg05380919 & $50 \%$ & $75 \%$ & $78 \%$ & $84 \% * *$ \\
\hline CYP3A5 & 7 & CS015290 & $\operatorname{cg} 03133378$ & $55 \%$ & $7 \%$ & $57 \%$ & $57 \%$ \\
\hline GSTM1 & 1 & rs75953876 & cg18938907 & $11 \%$ & $55 \%$ & $56 \%$ & $61 \%$ \\
\hline GPX7 & 1 & rs11810754 & cg11953272 & $48 \%$ & $16 \%$ & $49 \%$ & $52 \%$ \\
\hline UGT1A1 & 2 & rs7592624 & $\operatorname{cg} 11811840$ & $22 \%$ & $41 \%$ & $45 \%$ & $47 \%$ \\
\hline SLC22A18 & 11 & rs413781 & cg24724917 & $30 \%$ & $15 \%$ & $44 \%$ & $49 \% *$ \\
\hline FMO4 & 1 & rs2223477 & cg14981176 & $39 \%$ & $16 \%$ & $39 \%$ & $39 \%$ \\
\hline GSTM3 & 1 & rs115636764 & $\operatorname{cg} 23645476$ & $21 \%$ & $20 \%$ & $35 \%$ & $46 \% * *$ \\
\hline SLC19A1 & 21 & rs7867 & cg27210852 & $22 \%$ & $10 \%$ & $30 \%$ & $30 \%$ \\
\hline GSTO2 & 10 & rs11595547 & cg23659134 & $20 \%$ & $24 \%$ & $28 \%$ & $28 \%$ \\
\hline PON1 & 7 & rs854533 & cg07404485 & $13 \%$ & $23 \%$ & $27 \%$ & $30 \%$ \\
\hline DHRS2 & 14 & rs57350570 & cg07125017 & $23 \%$ & $4 \%$ & $26 \%$ & $26 \%$ \\
\hline GSTA4 & 6 & rs538920 & cg22486834 & $14 \%$ & $14 \%$ & $20 \%$ & $21 \%$ \\
\hline CEBPA & 19 & rs80241821 & cg19035908 & $17 \%$ & $6 \%$ & $20 \%$ & $20 \%$ \\
\hline MGST3 & 1 & rs10737515 & cg16553119 & $12 \%$ & $12 \%$ & $13 \%$ & $13 \%$ \\
\hline DHRST & 14 & rs376391 & cg18906360 & $12 \%$ & $9 \%$ & $13 \%$ & $13 \%$ \\
\hline
\end{tabular}

*F-test $\mathrm{p}$-value $<0.05 ;$ **F-test $\mathrm{p}$-value $<0.005$.

F-test null hypothesis: model for gene expression with the SNP and CpG site as explanatory variables and model for gene expression with the SNP and all CpG sites $^{1}$ fit equally well with the differences being due to random chance.

SNP and all CpG sites ${ }^{1}$ - the CpG sites that have eQTM effects with the expression probe. 
Figure 4 Venn diagram of the overlap of QTLs in four tested tissues. The number of overlapping (A) eQTL, (B) meQTLs, (C) eQTMs in shown for adult human liver, VAT, SAT and muscle samples.

As expected, we observed very strong tissue-specificity for the identified eQTMs. Only up to $4 \%$ of the eQTMs found in one tissue were also detectable with an identical effect direction in another tissue (Figure 4C, Additional file 16E).

Genes with adult-specific functions are enriched for eQTL We hypothesized that the expression of genes with important functions in the adult liver should be under strict genetic and epigenetic control. We thus focused on the set of probes with significantly higher and lower expression levels in adult liver compared to fetal liver (from the previous section "The transcriptome of the developing liver"), and formed a matched set of probes that were not differentially expressed between the two groups but displayed similar median expression levels and standard deviations in the adult liver samples. We observed that the expression of these adult liver-specific probes are much more likely to be affected by SNPs than the matched set of probes (1.43 times more than expected, chi-squared test $\mathrm{p}$-value $\left.=8.8 \times 10^{-7}\right)$. Furthermore, we observed that these probes were 1.24-fold enriched for liver-specific eQTL probes compared to a matched set of probes with eQTL in multiple tissues (chi-squared test $\mathrm{p}$-value $\left.=8.847 \times 10^{-6}\right)$. Vice versa, probes with lower expression levels in adult liver compared to fetal liver did not differ from the matched set of probes in terms of having eQTL and liver-specific eQTL effects. Furthermore, we did not observe any enrichment of meQTL in the adult liver-specific methylation probes.

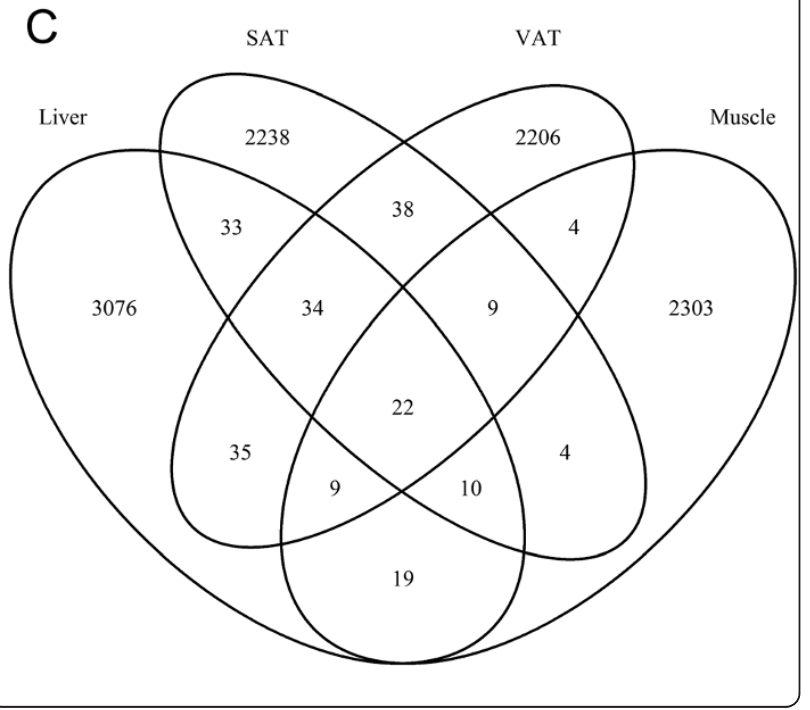

\section{Discussion}

Previous studies on the regulation of gene expression in human liver have only accounted for the effect of genetic variation in adult samples [7-11]. In this study, we investigated the developmental regulation of gene expression in human livers by comparing the expression and methylation levels of genes in adult and fetal livers. In addition, we used both genetic variants and DNA methylation differences in order to explain the variability in transcript levels observed in adult livers. Comparison of the fetal and adult liver methylomes and transcriptomes revealed that hypomethylated $\mathrm{CpG}$ sites and up-regulated genes were closely related to the tissue-specific functions: with fetal livers enriched for developmental and hematopoietic functions, while catabolic and metabolic processes were more prominent in adult livers. This has been described in the 
transcriptome of fetal livers at different stages of development in mice [23-25].

As the differences in methylation between fetal and adult livers were very large, when attempting to characterize the effects of variable methylation on gene expression levels in adults, we performed the eQTM analysis using a panel of only adult liver samples. Similarly to Gutierrez-Arcelus et al. [26], we observed both positive and negative correlations between DNA methylation and gene expression across the samples, with similar distributions across different genomic regions. Bell et al. have also observed a modest but significant excess of negative correlations between DNA methylation and variation in gene expression levels across individuals [27]. It has been reported that the role of DNA methylation appears to depend on the genomic context [28]: for example, CpG sites located near the genes and/or with a stronger correlation between the methylation and expression were more likely to display a negative correlation. Interestingly, CpG sites downstream of the expression probes displayed less negative correlations than those upstream of the probes, indicating that methylation in gene bodies is associated with active gene expression, as known from the early days of DNA methylation research [29,30]. This paradox - in which methylation in the promoter is negatively correlated with the expression, whereas methylation in the gene body is positively correlated with expression [30] - can be explained by the fact that, in mammals, DNA methylation silences the initiation of transcription, but not transcription elongation [28].

Our eQTL mapping in adult livers revealed 751 unique genes, which were strongly liver-specific and enriched for drug metabolizing functions. Of these, 84 genes were new associations, while others have already been reported $[7-10,22]$. The new associations are probably due to the larger number of samples and imputation of SNPs not present on previously used genotyping arrays, using data from the 1000 Genomes project. While we observed liverspecific associations with eQTL, the meQTL were not enriched for liver-specific functions. Furthermore, when we analyzed the SNPs that had significant effects on both methylation and expression, in most of the genes the same SNP allele had an opposite effect on gene expression compared to the methylation level, and this effect was most evident in CpG islands and shores (Additional file 10). These results show that, although there are many associations between SNPs and methylation levels, the relationships between them are not clear and do not reflect tissue-specific functions.

Inter-individual variability in ADME gene expression has been shown to affect drug efficacy, toxicity, and susceptibility to environmental toxins [31]. When we focused on the expression of ADME genes, we observed very strong cis-acting SNP and DNA methylation effects for 16 genes (Table 4), including members of the glutathione S-transferases (GSTs) family of phase II ADME isozymes: GSTA4, GSTM1, GSTM3, GSTO2 and GSTT1; solute carrier transporters SLC19A1 and SLC22A18, responsible for the transmembrane transfer of multiple drugs and endogenous compounds; and FMO4, GPX7, PON1 and UGT1A1. GSTT1 is involved in the conjugation of a variety of compounds [32-35], while GSTM1 functions in the detoxification of exogenous/endogenous toxins. The effects of epigenetic modifications on the expression of these genes have been reported in blood and brain tissues [36,37]. In our study, we observed that both SNPs and DNA methylation contribute to the variability of the expression of these genes. For example, the SNP rs2739330, downstream of the GSTT1 gene and upstream of the $D D T$ gene, has been reported to be associated with gamma-glutamyl transferase levels in plasma [38]. This SNP, together with methylation levels of a nearby CpG site cg05380919, explains 78\% of the variability in the expression of GSTT1, possibly with a stronger contribution from the methylation levels of the CpG site. Similarly, for GSTM1 the strongest SNP only explains $11 \%$ of the variation in its expression, while methylation levels of the CpG site cg18938907 has a much stronger association with the expression of the gene, and may be responsible for up to $55 \%$ of the variation (Additional file 11). The CpG site falls within a $\mathrm{CpG}$ island that spans the promoter and a portion of the gene's first intron. Interestingly, they are located near the transcription factor binding site of $T B P$, which has been shown to bind to the promoter of GSTM1 in HepG2 cells, according to ENCODE ChIP-Seq data.

A substantial portion of the overall phenotypic variance in hepatic enzyme PON1 activity between individuals remains unexplained. Besides a variety of non-genetic factors, numerous transcription factors [39] and miRNA regulation [40], various functional PON1 polymorphisms have been shown to influence serum PON1 levels and activity $[39,41]$. The SNP rs705379 has been shown to be associated with approximately 50\% mean reductions in serum PON1 protein levels as well as transcript levels $[41,42]$. In our study, it was interesting to see that this SNP was associated with increased methylation of nine CpG sites in its vicinity and with a lower expression of PON1.

Glutathione peroxidases (GPX) constitute a major antioxidative damage enzyme family [43] and are thus important in cancer therapy [44]. Not only genetic but also epigenetic mechanisms of gene regulation have been proposed for GPX7, while recently a CpG island was identified as a key player in regulating GPX7 expression [45]. In total, we identified 87 SNPs in the GPX7 gene affecting the methylation of nine CpG sites (meQTL), with six of the sites being directly implicated in quantitative 
differences in the gene expression. In addition, we replicated the two eQTL reported in human liver samples for GPX7 [10], and for the first time identified their association with differences in methylation of CpG sites, which are further correlated with changes in GPX7 expression levels. One of the expression-associated SNPs discovered in this study, rs11810754, appears to explain most of the variation in the expression levels of the gene (48\%), while the CpG site with the strongest correlation with expression (cg11953272) did not add any extra information to the variability of the expression of the gene (only $1 \%$, Table 4 ).

Three other tissues (muscle, SAT, VAT) were used to assess the tissue-specificity of both eQTL and meQTL effects. Our eQTL results showed that over half of the associations of SNPs with expression in one tissue could not be detected in another tissue (with identical eQTL allelic effect directions). This is similar to other studies $[7,9,11]$. In contrast, SNP-methylation correlations were much less tissue-specific than SNP-expression correlation: approximately $70 \%$ of the meQTL were also identified in any of the other tissues. To the best of our knowledge, this has not been described before, but could be due to sequence-dependent DNA methylation or the fact that genetic variation in a similarly methylated region can affect the entire region (given that we have excluded the direct effects of SNPs on methylation probes). On the other hand, we observed that DNA methylation associated with expression levels (i.e. eQTMs) are highly tissuespecific, in accordance with the fact that DNA methylation plays an important role in regulating tissue-specific gene expression. Thus, conclusions drawn from eQTL or eQTM data in one tissue cannot be extrapolated to other tissues, whereas the effect of SNPs on methylation is more likely to be detectable in an alternative tissue, for example DNA in blood, which is more readily accessible.

The greatest limitation of our study was the use of microarrays instead of massively parallel sequencing. Despite stringent filtering and remapping of expression and methylation probe sequences, we cannot rule out all technical artefacts inherent to microarray studies. Another drawback of microarrays is also their lower coverage of the genome, with the expression arrays only covering a few exons per gene, and the methylation array containing approximately $1 \%$ of the CpG sites in the human genome. Future studies using RNA and genome sequencing should be able to generate a more complete picture of the factors involved in the regulation of gene expression in human liver or other tissues.

\section{Conclusions}

By performing a genome-wide survey of genomic and epigenomic variation and their associations with gene expression in fetal and adult human liver, we have generated a comprehensive resource for the analysis of factors involved in the regulation of hepatic gene expression. The investigation of fetal livers allowed us to explore the developmental changes in the hepatic methylome and transcriptome. Although the role of DNA methylation in different regions of the genome is still unclear, our results elucidate the coordinated effects of SNPs and methylation, as well as the tissue specificity of their effects on gene expression. This strengthens the hypothesis that knowledge of inter-individual variability, driven by genetic polymorphisms and DNA methylation marks and their interaction, is crucial for understanding the causes of differences in drug response and the etiology of diseases associated with liver function.

\section{Methods}

The materials and methods of this study are described in detail in the Supplementary Online Methods in the Additional file 1. Briefly, our study was performed on two different cohorts, 14 fetal and 96 adult liver samples from the Karolinska Liver Bank cohort [46,47], and 85 adult samples from the Dutch tissue cohort MORE (BBMRI obesity cohort) $[11,48]$. For both datasets, the number of samples for which there is full expression, methylation and genotype data is not $100 \%$. We therefore report the number of samples per specific analysis. DNA from the samples were genotyped using HumanOmni BeadChips (Illumina), according to the manufacturer's instructions. We imputed both datasets using the GIANT release from the 1000 Genomes project, resulting in $5,763,069$ unique SNPs, which were used in all our downstream analyses. Gene expression data was generated using HumanHT-12 BeadChips (Illumina), according to the standard protocol. Bisulfite-converted DNA samples were hybridized to Infinium HumanMethylation450 BeadChips (Illumina), following the Illumina Infinium HD Methylation protocol.

\section{Availability of supporting data}

The data sets supporting the results of this article are available in the GEO repository, Dutch BBMRI more expression data: GSE22070; methylation data: GSE61454; Karolinska expression and methylation data: GSE61279.

\section{Additional files}

Additional file 1: Supplementary materials \& methods. Detailed descriptions of the samples and methods used; information about pre-processing, QTL mapping, eQTM analysis, explained variation analysis etc

Additional file 2: Differentially methylated genes between fetal and adult livers. A table listing the 28,917 significant CpG sites which are differentially methylated when comparing the methylation patterns of the adult liver with the fetal liver. 
Additional file 3: Average DNA methylation levels of all CpG sites on the $450 \mathrm{~K}$ beadchip and of differentially methylated $\mathrm{CpG}$ sites between adult and fetal livers. Proportion of $\mathrm{CpG}$ sites in (A) fetal livers and (B) adult livers with average beta-values between $0-0.25$ and 0.25-0.75 and 0.75-1 grouped by CpG island regions in three different groups based on the non-significant or significant differential methylation between fetal and adult livers.

Additional file 4: Differentially expressed genes between fetal and adult liver. A table listing the 3,284 expression probes which show significant differential expression when comparing the adult liver with the fetal liver.

Additional file 5: Differentially expressed and differentially methylated genes between fetal and adult livers. A table listing the 1,655 genes which are both differentially expressed and differentially methylated when comparing the fetal liver with adult liver. For every gene the direction of significant expression and methylation change in fetal compared to adult liver is given.

Additional file 6: Comparison of the expression levels of transcription factors in fetal and adult livers. A table listing the comparison of gene expression levels of transcription factors which are bioinformatically predicted to influence genes that are differentially expressed between adult and fetal livers.

Additional file 7: eQTMs identified in liver at FDR 0.05. Information on the $\mathrm{CpG}$ probe, expression probe and details including significance of the effects is given in this table.

Additional file 8: eQTL identified in liver at FDR 0.05. Information on the expression probe, SNP and details including significance of the effects is given in this table.

Additional file 9: Top 15,000 meQTL identified in liver. Information on the methylation probe, SNP and details including significance of the effects is given in this table. Full table available upon request (too large to upload).

Additional file 10: Distribution of opposite and identical effects of a SNP on gene expression and gene methylation. Proportion of genes with $\mathrm{eQTL}$ and meQTL depending on the effect of the SNP allele on gene expression compared to the methylation level grouped by $\mathrm{CpG}$ island regions.

Additional file 11: The contributions of SNPs and DNA methylation levels to the proportion of variation explained in gene expression levels. A table listing the genes by the proportion of the explained variation in gene expression by either a SNP (eQTL), a CpG site (eQTM), both a SNP and a CpG site (eQTL+eQTM) or a SNP and CpG sites (eQTL+eQTMs).

Additional file 12: Unique proportion of gene expression variation explained by a SNP or a CpG site. The figure outlines the expression variation explained uniquely by a SNP ( $x$-axis) vs the variation explained uniquely by a $\mathrm{CpG}$ site (y-axis). In general the SNPs explain more gene expression variation vs. a single $\mathrm{CpG}$ site, however there are some exceptions.

Additional file 13: Relation between the distance from TSS and the explained variation in gene expression by a CpG site and a SNP. Percentage of explained variation in gene expression by a $\mathrm{CpG}$ site or a SNP (y-axis) depending on the distance from the transcription start site of the corresponding genes ( $x$-axis).

Additional file 14: The contributions of SNPs and DNA methylation levels to the proportion of variation explained in gene expression levels of 16 ADME genes. Percentage of explained variation in gene expression of 16 ADME genes by a SNP (eQTL), a CpG (eQTM), both a SNP and a CpG site (eQTL+eQTM) or a SNP and CpG sites (eQTL+eQTMs).

Additional file 15: The contributions of SNPs and DNA methylation levels to the proportion of variation explained in gene expression levels of genes previously identified in GWA studies. A table listing the genes by the amount of the explained variation in expression of genes identified in GWA studies by either a SNP (eQTL), a CpG (eQTM), both a SNP and a CpG site (eQTL+eQTM) or a SNP and CpG sites (eQTL+eQTMs).
Additional file 16: Overlapping eQTL and meQTL with the same or opposite allelic direction and eQTMs with consistent direction identified in multiple tissues.

Additional file 17: meQTL with an opposite allelic direction between liver and the other three tissues. Illustration of a meQTL giving an opposite allelic effect in liver as compared to SAT, VAT and muscle. The C-allele of rs9768559 is associated with decreased methylation levels at a CpG site (cg07883117) in both the liver sample sets, while in SAT, VAT and muscle the same allele is associated with increased methylation levels at the same CpG site.

\section{Abbreviations}

ADME: Absorption, distribution, metabolism, and excretion; AUC: Area under the curve; CGI: CpG islands; eQTL: Expression quantitative trait loci; eQTM: Expression quantitative trait methylation; FDR: False discovery rate; GWA: Genome-wide association; meQTL: Methylation quantitative trait loci; SAT: Subcutaneous adipose tissue; SNP: Single nucleotide polymorphism; TSS: Transcription start site; VAT: Visceral adipose tissue.

\section{Competing interests}

The authors declare that they have no competing interests.

\section{Authors' contributions}

MJB, SK, LM and LF designed the study; MI, MIS, MW, WB, JWG, SR JVO and MHH collected and extracted the samples; MJB, SK and MK designed and performed the computational analyses; PD imputed the Dutch genotype data; MJB, SK, LM and LF interpreted the data and wrote the manuscript; $\mathrm{CW}, \mathrm{JF}, \mathrm{AZ}, \mathrm{RT}$ and IB participated in the interpretation of the data and provided input to the manuscript; $\mathrm{KL}$ participated in the data analysis. All authors provided input to the manuscript and read and approved the final manuscript.

\section{Acknowledgments}

We would like to thank The Target project (http://www.rug.nl/target) for providing the compute infrastructure and the BigGrid/eBioGrid project (http://www.ebiogrid.nl) for sponsoring the imputation pipeline implementation, the GCC for imputation, Soesma Medema for lab work (UMCG), and Jackie Senior (UMCG) for editing. We would also like to acknowledge the staff at the Core Facility of the Estonian Genome Center, University of Tartu, for performing the microarray experiments of the Karolinska samples.

\section{Financial support}

This work is supported by grants from the Estonian Science Foundation (ETF9293), the European Union through the European Social Fund (MJD71), the European Regional Development Fund in the framework of the Centre of Excellence in Genomics (EXCEGEN), the University of Tartu (SP1GVARENG), the Estonian Research Council (IUT20-60), the Swedish Research Council, the Seurat 1 NOTOX project, the Marie Curie CIG 322283, IOP Genomics grant IGE05012A, the Netherlands Organization for Scientific Research (NWO), an NWO VENI grant 916.10.135, an NWO VENI grant 863.09.007, a Horizon Breakthrough grant from the Netherlands Genomics Initiative (grant 92519031), Systems Biology Centre for Metabolism and Ageing (SBC-EMA) and BBMRI (RP2/RP3/Complementatieproject BBMRI-NL-CP2013-71). The research leading to these results has received funding from the European Community's Health Seventh Framework Programme (FP7/2007-2013) under grant agreement no. 259867

\section{Author details}

${ }^{1}$ University of Groningen, University Medical Center Groningen, Department of Genetics, Hanzeplein 1, 9700 RB Groningen, the Netherlands. ${ }^{2}$ Estonian Genome Center, University of Tartu, Riia 23 B, 51010 Tartu, Estonia. Institute of Molecular and Cell Biology, University of Tartu, Tartu, Estonia. ${ }^{4}$ Institute of Mathematical Statistics, University of Tartu, Tartu, Estonia. ${ }^{5}$ Section of Pharmacogenetics, Department of Physiology and Pharmacology, Karolinska Institutet, Stockholm, Sweden. ${ }^{6}$ Department of Surgery, University Hospital Maastricht and Nutrition and Toxicology Research Institute (NUTRIM), Maastricht University, Maastricht, the Netherlands. 'University of Groningen, University Medical Center Groningen, Genomics Coordination Center, Groningen, the Netherlands. ${ }^{8}$ Department of General Surgery, Atrium Medical 
Center Parkstad, Heerlen, the Netherlands. 'University of Groningen, University Medical Center Groningen, Department of Endocrinology, Groningen, the Netherlands. ${ }^{10}$ University of Groningen, University Medical Center Groningen, Unit of Genetic Epidemiology and Bioinformatics, Department of Epidemiology, Groningen, the Netherlands. "'University of Groningen, University Medical Center Groningen, Department of Pathology and Medical Biology, Molecular Genetics section, Groningen, the Netherlands.

\section{Received: 19 May 2014 Accepted: 24 September 2014}

Published: 4 October 2014

\section{References}

1. Sabatti C, Service SK, Hartikainen A-L, Pouta A, Ripatti S, Brodsky J, Jones CG, Zaitlen NA, Varilo T, Kaakinen M, Sovio U, Ruokonen A, Laitinen J, Jakkula E, Coin L, Hoggart C, Collins A, Turunen H, Gabriel S, Elliot P, McCarthy Ml, Daly MJ, Järvelin M-R, Freimer NB, Peltonen L: Genome-wide association analysis of metabolic traits in a birth cohort from a founder population. Nat Genet 2009, 41:35-46.

2. Qi L, Cornelis MC, Kraft P, Stanya KJ, Linda Kao WH, Pankow JS, Dupuis J, Florez JC, Fox CS, Paré G, Sun Q, Girman CJ, Laurie CC, Mirel DB, Manolio TA, Chasman DI, Boerwinkle E, Ridker PM, Hunter DJ, Meigs JB, Lee C-H, Hu FB, van Dam RM: Genetic variants at 2q24 are associated with susceptibility to type 2 diabetes. Hum Mol Genet 2010, 19:2706-2715.

3. Voight BF, Scott LJ, Steinthorsdottir V, Morris AP, Dina C, Welch RP, Zeggini E, Huth C, Aulchenko YS, Thorleifsson G, McCulloch L」, Ferreira T, Grallert H, Amin N, Wu G, Willer CJ, Raychaudhuri S, McCarroll SA, Langenberg C, Hofmann OM, Dupuis J, Qi L, Segrè AV, van Hoek M, Navarro P, Ardlie K, Balkau B, Benediktsson R, Bennett AJ, Blagieva R: Twelve type 2 diabetes susceptibility loci identified through large-scale association analysis. Nat Genet 2010, 42:579-589.

4. Suhre K, Shin S-Y, Petersen A-K, Mohney RP, Meredith D, Wägele B, Altmaier E, Deloukas P, Erdmann J, Grundberg E, Hammond CJ, de Angelis MH, Kastenmüller G, Köttgen A, Kronenberg F, Mangino M, Meisinger C, Meitinger T, Mewes H-W, Milburn MV, Prehn C, Raffler J, Ried JS, RömischMargl W, Samani NJ, Small KS, Wichmann H-E, Zhai G, Illig T, Spector TD: Human metabolic individuality in biomedical and pharmaceutical research. Nature 2011, 477:54-60.

5. Adams LA, White SW, Marsh JA, Lye SJ, Connor KL, Maganga R, Ayonrinde OT, Olynyk JK, Mori TA, Beilin L, Palmer L, Hamdorf JM, Pennell CE: Association between liver-specific gene polymorphisms and their expression levels with nonalcoholic fatty liver disease. Hepatology 2013, 57:590-600

6. Ellinghaus D, Folseraas T, Holm K, Ellinghaus E, Melum E, Balschun T, Laerdahl JK, Shiryaev A, Gotthardt DN, Weismüller TJ, Schramm C, Wittig M, Bergquist A, Björnsson E, Marschall H-U, Vatn M, Teufel A, Rust C, Gieger C, Wichmann H-E, Runz H, Sterneck M, Rupp C, Braun F, Weersma RK, Wijmenga C, Ponsioen CY, Mathew CG, Rutgeerts P, Vermeire S: Genome-wide association analysis in primary sclerosing cholangitis and ulcerative colitis identifies risk loci at GPR35 and TCF4. Hepatology 2013, 58:1074-1083.

7. Schadt EE, Molony C, Chudin E, Hao K, Yang X, Lum PY, Kasarskis A, Zhang B, Wang S, Suver C, Zhu J, Millstein J, Sieberts S, Lamb J, GuhaThakurta D, Derry J, Storey JD, Avila-Campillo I, Kruger MJ, Johnson JM, Rohl CA, van Nas A, Mehrabian M, Drake TA, Lusis AJ, Smith RC, Guengerich FP, Strom SC, Schuetz E, Rushmore TH: Mapping the genetic architecture of gene expression in human liver. PLoS Biol 2008, 6:e107.

8. Greenawalt DM, Dobrin R, Chudin E, Hatoum IJ, Suver C, Beaulaurier J, Zhang B, Castro V, Zhu J, Sieberts SK, Wang S, Molony C, Heymsfield SB, Kemp DM, Reitman ML, Lum PY, Schadt EE, Kaplan LM: A survey of the genetics of stomach, liver, and adipose gene expression from a morbidly obese cohort. Genome Res 2011, 21:1008-1016.

9. Innocenti F, Cooper GM, Stanaway IB, Gamazon ER, Smith JD, Mirkov S, Ramirez J, Liu W, Lin YS, Moloney C, Aldred SF, Trinklein ND, Schuetz E, Nickerson DA, Thummel KE, Rieder MJ, Rettie AE, Ratain MJ, Cox NJ, Brown CD: Identification, replication, and functional fine-mapping of expression quantitative trait loci in primary human liver tissue. PLoS Genet 2011, 7:e1002078.

10. Schröder A, Klein K, Winter S, Schwab M, Bonin M, Zell A, Zanger UM: Genomics of ADME gene expression: mapping expression quantitative trait loci relevant for absorption, distribution, metabolism and excretion of drugs in human liver. Pharmacogenomics J 2013, 13:12-20.

11. Fu J, Wolfs MGM, Deelen P, Westra H-J, Fehrmann RSN, Te Meerman GJ, Buurman WA, Rensen SS, Groen HJ, Weersma RK, van den Berg LH, Veldink J, Ophoff RA, Snieder H, van Heel D, Jansen RC, Hofker MH, Wijmenga C, Franke L: Unraveling the regulatory mechanisms underlying tissuedependent genetic variation of gene expression. PLOS Genet 2012, 8:e1002431.

12. Lister R, Pelizzola M, Dowen RH, Hawkins RD, Hon G, Tonti-Filippini J, Nery JR, Lee L, Ye Z, Ngo Q-M, Edsall L, Antosiewicz-Bourget J, Stewart R, Ruotti $\mathrm{V}$, Millar AH, Thomson JA, Ren B, Ecker JR: Human DNA methylomes at base resolution show widespread epigenomic differences. Nature 2009, 462:315-322.

13. Ghosh S, Yates AJ, Frühwald MC, Miecznikowski JC, Plass C, Smiraglia D: Tissue specific DNA methylation of CpG islands in normal human adult somatic tissues distinguishes neural from non-neural tissues. Epigenetics 2010, 5:527-538.

14. Varley KE, Gertz J, Bowling KM, Parker SL, Reddy TE, Pauli-Behn F, Cross MK Williams BA, Stamatoyannopoulos JA, Crawford GE, Absher DM, Wold BJ, Myers RM: Dynamic DNA methylation across diverse human cell lines and tissues. Genome Res 2013, 23:555-567.

15. Ghotbi R, Gomez A, Milani L, Tybring G, Syvänen AC, Bertilsson L, IngelmanSundberg $M$, Aklillu E: Allele-specific expression and gene methylation in the control of CYP1A2 mRNA level in human livers. Pharmacogenomics $J$ 2009, 9:208-217.

16. Thomson JP, Hunter JM, Lempiäinen H, Müller A, Terranova R, Moggs JG, Meehan RR: Dynamic changes in 5-hydroxymethylation signatures underpin early and late events in drug exposed liver. Nucleic Acids Res 2013, 41:5639-5654.

17. Chen WD, Fu X, Dong B, Wang YD, Shiah S, Moore DD, Huang W: Neonatal activation of the nuclear receptor CAR results in epigenetic memory and permanent change of drug metabolism in mouse liver. Hepatology 2012, 56:1499-1509.

18. Kacevska M, Ivanov M, Ingelman-Sundberg M: Epigenetic-dependent regulation of drug transport and metabolism: an update. Pharmacogenomics 2012, 13:1373-1385.

19. McLean CY, Bristor D, Hiller M, Clarke SL, Schaar BT, Lowe CB, Wenger AM, Bejerano G: GREAT improves functional interpretation of cis-regulatory regions. Nat Biotechnol 2010, 28:495-501.

20. Cvejic A, Haer-Wigman L, Stephens JC, Kostadima M, Smethurst PA, Frontini $M$, van den Akker E, Bertone P, Bielczyk-Maczyńska E, Farrow S, Fehrmann RSN, Gray A, de Haas M, Haver VG, Jordan G, Karjalainen J, Kerstens HHD, Kiddle G, Lloyd-Jones H, Needs M, Poole J, Soussan AA, Rendon A, Rieneck K, Sambrook JG, Schepers H, Silljé HHW, Sipos B, Swinkels D, Tamuri AU: SMIM1 underlies the Vel blood group and influences red blood cell traits. Nat Genet 2013, 45:542-545.

21. Moscovitz JE, Aleksunes LM: Establishment of metabolism and transport pathways in the rodent and human fetal liver. Int J Mol Sci 2013, 14:23801-23827.

22. Yang X, Zhang B, Molony C, Chudin E, Hao K, Zhu J, Gaedigk A, Suver C, Zhong H, Leeder JS, Guengerich FP, Strom SC, Schuetz E, Rushmore TH, Ulrich RG, Slatter JG, Schadt EE, Kasarskis A, Lum PY: Systematic genetic and genomic analysis of cytochrome P450 enzyme activities in human liver. Genome Res 2010, 20:1020-1036.

23. Lee JS, Ward WO, Knapp G, Ren H, Vallanat B, Abbott B, Ho K, Karp SJ, Corton JC: Transcriptional ontogeny of the developing liver. BMC Genomics 2012, 13:33.

24. Jochheim-Richter A, Rüdrich U, Koczan D, Hillemann T, Tewes S, Petry M, Kispert A, Sharma AD, Attaran F, Manns MP, Ott M: Gene expression analysis identifies novel genes participating in early murine liver development and adult liver regeneration. Differentiation 2006, 74:167-173.

25. Li T, Huang J, Jiang Y, Zeng Y, He F, Zhang MQ, Han Z, Zhang X: Multistage analysis of gene expression and transcription regulation in C57/B6 mouse liver development. Genomics 2009, 93:235-242.

26. Gutierrez-Arcelus M, Lappalainen T, Montgomery SB, Buil A, Ongen H, Yurovsky A, Bryois J, Giger T, Romano L, Planchon A, Falconnet E, Bielser D, Gagnebin M, Padioleau I, Borel C, Letourneau A, Makrythanasis P, Guipponi M, Gehrig C, Antonarakis SE, Dermitzakis ET: Passive and active DNA methylation and the interplay with genetic variation in gene regulation. Elife 2013, 2:e00523. 
27. Bell JT, Spector TD: DNA methylation studies using twins: what are they telling us? Genome Biol 2012, 13:172.

28. Jones PA: Functions of DNA methylation: islands, start sites, gene bodies and beyond. Nat Rev Genet 2012, 13:484-492.

29. Wolf SF, Jolly DJ, Lunnen KD, Friedmann T, Migeon BR: Methylation of the hypoxanthine phosphoribosyltransferase locus on the human $\mathrm{X}$ chromosome: implications for X-chromosome inactivation. Proc Natl Acad Sci U S A 1984, 81:2806-2810.

30. Jones PA: The DNA methylation paradox. Trends Genet 1999, 15:34-37.

31. Ingelman-Sundberg M, Sim SC, Gomez A, Rodriguez-Antona C: Influence of cytochrome P450 polymorphisms on drug therapies: pharmacogenetic, pharmacoepigenetic and clinical aspects. Pharmacol Ther 2007. 116:496-526.

32. Marinković N, Pasalić D, Potocki S: Polymorphisms of genes involved in polycyclic aromatic hydrocarbons' biotransformation and atherosclerosis. Biochem Med (Zagreb) 2013, 23:255-265.

33. Tulsyan S, Chaturvedi P, Agarwal G, Lal P, Agrawal S, Mittal RD, Mittal B: Pharmacogenetic influence of GST polymorphisms on anthracyclinebased chemotherapy responses and toxicity in breast cancer patients: a multi-analytical approach. Mol Diagn Ther 2013, 17:371-379.

34. Ramos DL, Gaspar JF, Pingarilho M, Gil OM, Fernandes AS, Rueff J, Oliveira NG: Genotoxic effects of doxorubicin in cultured human lymphocytes with different glutathione S-transferase genotypes. Mutat Res 2011, 724:28-34.

35. Zhong $S$, Huang M, Yang $X$, Liang L, Wang Y, Romkes M, Duan W, Chan E, Zhou SF: Relationship of glutathione S-transferase genotypes with sideeffects of pulsed cyclophosphamide therapy in patients with systemic lupus erythematosus. Br J Clin Pharmacol 2006, 62:457-472.

36. Liu Y, Ding J, Reynolds LM, Lohman K, Register TC, De La Fuente A, Howard TD, Hawkins GA, Cui W, Morris J, Smith SG, Barr RG, Kaufman JD, Burke GL, Post W, Shea S, McCall CE, Siscovick D, Jacobs DR, Tracy RP, Herrington DM, Hoeschele I: Methylomics of gene expression in human monocytes. Hum Mol Genet 2013, 22:5065-5074.

37. Sintupisut N, Liu PL, Yeang CH: An integrative characterization of recurrent molecular aberrations in glioblastoma genomes. Nucleic Acids Res 2013, 41:8803-8821.

38. Chambers JC, Zhang W, Sehmi J, Li X, Wass MN, Van der Harst P, Holm H, Sanna S, Kavousi M, Baumeister SE, Coin L, Deng G, Gieger C, Heard-Costa NL, Hottenga J-J, Kühnel B, Kumar V, Lagou V, Liang L, Luan J, Vidal PM, Mateo Leach I, O'Reilly PF, Peden JF, Rahmioglu N, Soininen P, Speliotes EK, Yuan X, Thorleifsson G, Alizadeh BZ: Genome-wide association study identifies loci influencing concentrations of liver enzymes in plasma. Nat Genet 2011, 43:1131-1138.

39. Fuhrman B: Regulation of hepatic paraoxonase-1 expression. J Lipids 2012, 2012:684010.

40. Liu ME, Liao YC, Lin RT, Wang YS, Hsi E, Lin HF, Chen KC, Juo SH: A functional polymorphism of PON1 interferes with microRNA binding to increase the risk of ischemic stroke and carotid atherosclerosis. Atherosclerosis 2013, 228:161-167.

41. Deakin S, Leviev I, Brulhart-Meynet MC, James RW: Paraoxonase-1 promoter haplotypes and serum paraoxonase: a predominant role for polymorphic position - 107, implicating the Sp1 transcription factor. Biochem J 2003, 372:643-649.

42. Brophy VH, Hastings MD, Clendenning JB, Richter RJ, Jarvik GP, Furlong CE: Polymorphisms in the human paraoxonase (PON1) promoter. Pharmacogenetics 2001, 11:77-84

43. Miyamoto Y, Koh YH, Park YS, Fujiwara N, Sakiyama H, Misonou Y, Ookawara T, Suzuki K, Honke K, Taniguchi N: Oxidative stress caused by inactivation of glutathione peroxidase and adaptive responses. Biol Chem 2003, 384:567-574.

44. Yang P, Ebbert JO, Sun Z, Weinshilboum RM: Role of the glutathione metabolic pathway in lung cancer treatment and prognosis: a review. J Clin Oncol 2006, 24:1761-1769.

45. Peng D, Hu T, Soutto M, Belkhiri A, Zaika A, El-Rifai W: Glutathione peroxidase 7 has potential tumour suppressor functions that are silenced by location-specific methylation in oesophageal adenocarcinoma. Gut 2014, 63:540-551.

46. Kacevska M, Ivanov M, Wyss A, Kasela S, Milani L, Rane A, IngelmanSundberg M: DNA methylation dynamics in the hepatic CYP3A4 gene promoter. Biochimie 2012, 94:2338-2344.
47. Ivanov M, Kals M, Kacevska M, Barragan I, Kasuga K, Rane A, Metspalu A, Milani L, Ingelman-Sundberg M: Ontogeny, distribution and potential roles of 5-hydroxymethylcytosine in human liver function. Genome Biol 2013, 14:R83.

48. Wolfs MGM, Rensen SS, Bruin-Van Dijk EJ, Verdam FJ, Greve J-W, Sanjabi B, Bruinenberg M, Wijmenga C, van Haeften TW, Buurman WA, Franke L, Hofker MH: Co-expressed immune and metabolic genes in visceral and subcutaneous adipose tissue from severely obese individuals are associated with plasma HDL and glucose levels: a microarray study. BMC Med Genomics 2010, 3:34.

doi:10.1186/1471-2164-15-860

Cite this article as: Bonder et al:: Genetic and epigenetic regulation of gene expression in fetal and adult human livers. BMC Genomics 2014 15:860

\section{Submit your next manuscript to BioMed Central and take full advantage of:}

- Convenient online submission

- Thorough peer review

- No space constraints or color figure charges

- Immediate publication on acceptance

- Inclusion in PubMed, CAS, Scopus and Google Scholar

- Research which is freely available for redistribution 